\title{
The Principled Approach to Ventral Hernia Repair
}

\author{
El abordaje basado en principios para el reparo de la hernia ventral \\ Jorge Daes $\mathrm{MD}^{1}$, Dana Telem MD, $\mathrm{MPH}^{2}$
}

1 Academic Director, Department of Minimally Invasive Surgery, Clinica Portoazul, Barranquilla, Colombia

2 Department of Surgery, University of Michigan

\begin{abstract}
Standardization of ventral hernia repair remains elusive. Surgeons use a plethora of techniques, tools, and technology to repair similar defects. Nevertheless, evidence-based principles exist that should be applied to all repairs irrespective of technique allowing standardization and improved outcomes. Six principles are proposed as the basis for complex abdominal wall reconstruction.
\end{abstract}

Keywords: hernia, ventral; abdominal wall reconstruction; surgical procedures; herniorrhaphy; surgical mesh; prostheses and implants.

\section{Resumen}

La estandarización de la reparación de la hernia ventral sigue siendo difícil de alcanzar. Los cirujanos utilizan una gran cantidad de técnicas, herramientas y tecnología para reparar defectos similares. Sin embargo, existen principios basados en la evidencia que deben aplicarse a todas las reparaciones, independientemente de la técnica que permita la estandarización y mejores resultados. Se proponen seis principios como base para la reconstrucción compleja de la pared abdominal.

Palabras clave: ventral hernia; reconstrucción de pared abdominal; procedimientos quirúrgicos; herniorrafia; mallas quirúrgicas; prótesis e implantes.

\section{Introduction}

Ventral hernia still represents the "wild west" of surgery practice. Evidence-based consensus on optimal operative techniques by patient and hernia type does not exist. Additionally, almost daily a new technique is introduced and rapidly disseminated via novel platforms. Arguments over operative approach (e.g., robotic, laparoscopic, open), mesh location, fixation and extension, and methods of fascial closure persist. This variability in approach is mirrored by the variability in patient outcomes following repair. Up to 20 in Ioo patients undergoing hernia repair will have an adverse event (e.g., wound complication, recurrence of the hernia) '. Annually, over 3.2 billion of healthcare dollars are spent managing abdominal wall hernia and its complications ${ }^{2}$.

Fecha de recibido: 14/12/2018 - Fecha aceptación: 18/12/2018

Corresponding author: Jorge Daes MD, MACC, FACS Carrera 30, Corredor Universitario \#1-850, Consultorio 411, Barranquilla, Colombia. Mobile: (57) 310633636; Fax (57) (5) 3604666

E-mail jorgedaez@gmail.com

Citar como: Daes J, Telem D. The principled approach to ventral hernia repair. Rev Colomb Cir. 2019;34:25-8. https://doi.org/10.30944/20117582.94

Este es un artículo de acceso abierto bajo una Licencia Creative Commons - BY-NC-ND https://creativecommons.org/licenses/by-nc-nd/4.0/deed.es 
A lack of comparative effectiveness data ensures that we are a long way from standardization of hernia repair to any particular technique. Nevertheless, evidence-based principles exist that should be applied to all repairs irrespective of technique selected. Incorporating these principles into every day practice allows a surgeon to base a complex ventral hernia repair not on a particular technique but on principles that have consistently resulted in improved outcomes. Thus, the following principles are proposed as the basis for complex abdominal wall reconstruction:

I. Primary closure of facial defects under physiologic tension when possible.

2. Wide prosthetic reinforcement of the visceral sac.

3. Limited fixation of prosthetic material.

4. Sublay placement of meshes is preferable, although alternative placement is acceptable.

5. Minimally invasive (MI) approach when feasible.

6. Patient prehabilitation.

7. Enhanced Recovery After Surgery (ERAS) protocol.

\section{Justification}

Principle I: Primary closure of facial defects under physiologic tension.

Primary closure of defects and reestablishing the linea alba under physiologic tension have been the mainstays of open repairs and recently have been considered essential components of minimally invasive abdominal wall reconstruction (AWR). Although we do not have definitive evidence in the form of a randomized, controlled trial, studies summarized by Nguyen et al. ${ }^{3}$, demonstrate less seroma formation, fewer recurrences, and less mesh eventration with primary closure of defects. There is also evidence of better cosmesis and abdominal wall function ${ }^{4}$.

Principle 2: Wide prosthetic reinforcement of the visceral sac.

Wide prosthetic reinforcement of the visceral sac, first described by Stoppa as a highly effective repair for complex inguinal hernias ${ }^{5}$, has been applied to the repair of ventral hernias. Posterior component separation-transversus abdominis release (PCS-TAR) is one of the best examples of such reinforcement, with its excellent long-term results and low morbidity following extremely complex ventral hernia repair ${ }^{6}$. The open RivesStoppa repair fulfills most of the principles so long as the size of the defect allows closure under physiologic tension and wide mesh reinforcement ${ }^{7}$.

More recently, the enhanced-view, totally extraperitoneal (eTEP) access, Rives Stoppa / TAR technique has produced similar results in selected cases ${ }^{8}$. Other techniques, such as the open anterior component separation onlay repair, could be included in this group, although they may not comply with principles 3,4 , and 5 because of their inherent characteristics. Intraperitoneal onlay mesh repairs with primary closure of defects (IPOM-plus) are also highly effective in selected cases ${ }^{9}$. However, IPOMplus does not comply with some of the proposed principles, such as the position of the mesh, and is associated with the potential for adhesion formation and the need for strong fixation and its consequences.

Principle 3: Limited fixation of the prosthetic material.

The use of limited mesh fixation can address quality of life issues, especially by reducing postoperative pain. Limited or no fixation of meshes is possible when principles I, 2 and 4 are followed. This measure may be the most important factor in the recent decrease in postoperative pain and length of hospital stay reported when using more recent, minimally invasive approaches ${ }^{8}$.

Principle 4: Sublay placement of meshes is preferred.

Although other mesh positions are acceptable, a sublay (e.g., retromuscular, preperitoneal) position for mesh placement is preferred. A sublay mesh position for AWR makes sense from the physical point of view. Laplace's law 
and Pascal's principle support this positioning of meshes and primary closing of defects. Sublay placement of a proper-sized mesh makes aggressive fixation unnecessary. It also permits the use of nonprotected meshes, lowering the cost of the procedure 9 . A Danish registry study concluded that sublay position of meshes resulted in the lowest risk of long term reoperation when compared to intraperitoneal and onlay

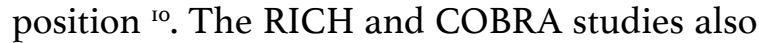
have demonstrated a significant reduction on recurrence with retro-muscular position of meshes in comparison with intraperitoneal placement ${ }^{\mathrm{II}, \mathrm{I}}$. Alternative positioning of meshes, such as underlay and onlay meshes, is acceptable if proper meshes are placed, a sound technique is performed, and the meshes are placed in the right patient. However, these alternative positions of meshes do not benefit from the advantages cited above.

Principle 5: Minimally invasive (MI) approach when feasible.

Since their introduction, minimally invasive approaches for AWR have demonstrated advantages over open approaches ${ }^{13}$. They reduce surgical-site events, most notably infection, shorten hospitalizations and accelerate recovery. Adequate selection of cases, proper training, and equipment are prerequisites for a successful MI ventral hernia repair. MI approaches are limited in very complex abdominal reconstructions. Robotic surgery with its $3 \mathrm{D}$ vision, better ergonomics, curved instruments and improved suturing capabilities may offset some of this limitations and may provide benefit in terms of length of stay based on the Americas Hernia Society Quality Collaborative data ${ }^{14}$. Less invasive open approaches should be used to reduce morbidity - for example, preserving division of perforators during the anterior component separation.

Principle 6: Patient Prehabilitation.

Numerous studies demonstrate outcome differential based on patient characteristics. It is well accepted that active tobacco users, patients with morbid obesity, diabetes and those who are immunosuppressed are at higher risk of perioperative complication and longer-term recurrence. Smoking cessation, MRSA eradication, weight loss, and optimization of glycemic control should be performed or strongly considered prior to an elective hernia repair ${ }^{15}$.

Principle 7: Enhanced Recovery After Surgery (ERAS) protocol.

ERAS have been validated in a series of welldesigned studies that have reported reduced morbidity, better quality of life, and lower costs when implemented in AWR protocols ${ }^{16}$. While ERAS pathways vary from center to center, they represent an important next step in the evolution of overall care of complex hernia patients.

The application of these principles must be tailored according to the characteristics of the surgeons, including their local resources, their patients, and the type of hernias. Complex AWRs are probably most benefited by the application of all of the proposed principles, whereas less complex cases can usually be repaired following only some of them to avoid overtreatment. Many of the principles are interdependent and cannot be implemented without enforcing others. Finally, these principles are not the final word and will be adapted as new and relevant evidence is revealed. Surgeons are encouraged to be involved in high quality studies on ventral hernia surgery.

\section{Conclusion}

The high variability in how ventral hernias are currently approached makes it difficult to evaluate and compare results, establish treatment consensus or standardize techniques. Focusing on evidence-based principles rather than technique is advantageous to reduce variability, compare and evaluate repairs, and facilitate education and training.

\section{References}

I. Flum DR, Horvath K, Koepsell T (2003) Have outcomes of incisional hernia repair improved with time? A population-based analysis. Ann Surg. 2003;237:129-35. 
2. Poulose BK, Shelton J, Phillips S, Moore D, Nealon W, Penson D, Beck W, Holzman MD. Epidemiology and cost of ventral hernia repair: making the case for hernia research. Hernia. 2012;16:179-83.

3. Nguyen DH, Nguyen MT, Askenasy EP, Kao LS, Liang MK. Primary fascial closure with laparoscopic ventral hernia repair: Systematic review. World J Surg. 20I4;38:3097-I04.

4. den Hartog D, Eker HH, Tuinebreijer WE, Kleinrensink GJ, Stam HJ, Lange JF. Isokinetic strength of the trunk flexor muscles after surgical repair for incisional hernia. Hernia. 20I0; I4: 243-7.

5. Wantz GE. Giant prosthetic reinforcement of the visceral sac. The Stoppa groin hernia repair. Surg Clin N Am. 1998;78:I075-87.

6. Novitsky YW, Fayezizadeh M, Majumder A, Neupane R, Elliott HL, Orenstein SB. Outcomes of posterior component separation with transversus abdominis muscle release and sublay mesh reinforcement. Ann Surg. 2016; 264 :226-32

7. Ramaswamy A. Laparoscopic ventral hernia repair. Disponible en https://www.sages.org/wiki/laparoscopic-ventral-hernia-repair. Fecha de descarga: Diciembre I4 de 2018.

8. Belyansky I, Daes J, Radu VG, Balasubramanian R, Reza Zahiri H, Weltz AS, Sibia US, Park A, Novitsky Y. A novel approach using the enhanced-view totally extraperitoneal (eTEP) technique for laparoscopic retromuscular hernia repair. Surg Endosc. 2018;32:1525-32.

9. Daes J, Dennis RJ. Endoscopic subcutaneous component separation as an adjunct to abdominal wall reconstruction. Surg Endosc. 20I6; 31:872-6.
Io. Helgstrand F, Rosenberg J, Kehlet H, Jorgensen L, Bisgaard T. Nationwide Prospective Study of Outcomes after Elective Incisional Hernia Repair. J Am Coll Surg. 2012;216:217-28.

II. Itani KM, Rosen M, Vargo D, Awad SS, Denoto G, Butler CE. Prospective study of single-stage repair of contaminated hernias using a biologic porcine tissue matrix: the RICH Study. Surgery. 2012;152:498-505.

I2. Rosen M, Bauer J, Harmaty M, Carbonell A, Cobb W. Matthews B, Goldblatt MI, Selzer DJ, Poulose BK, Hansson BM, Rosman C, Chao JJ, Jacobsen GR. Multicenter, Prospective, Longitudinal Study of the Recurrence, Surgical Site Infection, and Quality of Life After Contaminated Ventral Hernia Repair Using Biosynthetic Absorbable Mesh: The COBRA Study. Ann Surg. 20I7; 265:205-II.

13. LeBlanc KA, Booth WV. Laparoscopic repair of incisional abdominal hernias using expanded polytetrafluoroethylene: Preliminary findings. Surg Laparosc Endosc. 1993; 3:39-4I.

I4. Warren JA, Cobb WS, Ewing JA, Carbonell AM. Standard laparoscopic versus robotic retromuscular ventral hernia repair. Surg Endosc. 2017;31:324-32.

I5. Petro C, Prabhu A. Preoperative planning and patient optimization. Surg Clin N Am. 20I8; 98:483-97.

I6. Majumder A, Fayezizadeh M, Neupane RL, Elliott H, Novitsky Y. Benefits of multimodal enhanced recovery pathway in patients undergoing open ventral hernia repair. J Am Coll Surg. 20I6; 222:IIO6-I5. 